\title{
RESEARCH
}

Open Access

\section{Nasal spray live attenuated influenza vaccine: the first experience in Italy in children and adolescents during the 2020-21 season}

Chiara Gasparini ${ }^{* *}$ (D, Miriam Acunzo ${ }^{1}$, Andrea Biuso1, Stefania Roncaglia', Francesca Migliavacca1, Catia R. Borriello², Caterina Bertolini ${ }^{2}$, Michaela R. Allen ${ }^{3}$, Annalisa Orenti ${ }^{4}$, Patrizia Boracchi $^{4}$ and Gian Vincenzo Zuccotti ${ }^{1}$

\begin{abstract}
Background: In Italy only recently, for the 2020-21 season, has the flu vaccination been extended to all children. A quadrivalent live attenuated influenza vaccine (qLAIV) was administered to children aged 2-17 years for the first time.

We registered the number and severity of adverse reactions to (Fluenz Tetra ${ }^{\mathrm{TM}}$ ) and the factors influencing them, evaluated uniformity of access to care and assessed the degree of satisfaction with the vaccination of both parents and health care providers, in order to improve the 2021-22 vaccination program.

Methods: On vaccination day, a questionnaire was given out to collect information about the children and their parents. Between 1 and 3 months later, the parents were contacted to record any adverse reactions following (Fluenz Tetra ${ }^{\mathrm{TM}}$ ) and rate the degree of satisfaction.

Results: We received data of 3226 children from 2152 families.

Adverse events were reported in $24.8 \%$ of children: $80.6 \%$ mild, $18.1 \%$ moderate and $1.3 \%$ significant. The most common were rhinitis (52.5\%) and fever (24.4\%). Statistical analysis performed with a multiple regression model, showed that children aged 2-5 years have an increased risk of adverse events compared to both $6-10$ years old (aRR 1.7, 95\% Cl 1.5-1.9, $p<0.001$ ) and 11-17 years old (aRR 1.5, 95\% Cl 1-2.2, $p=0.051$ ).

Most families chose to vaccinate their children to protect them and because they were concerned about Covid19.

The main channel through which parents became aware of a new flu vaccination was word-of-mouth (39.8\%), which occurred mostly among parents of the same school group, followed by information from the child's doctor (30.6\%), the Internet (26.9\%), personal research (15\%), newspapers (4\%), telecommunications (7.5\%) and other (2.6\%). Most parents (83.3\%) were very satisfied and intend to vaccinate their children with qLAIV again (83.8\%). The majority of operators (93\%) considered the experience as excellent and are willing to repeat it (94.6\%).
\end{abstract}

\footnotetext{
* Correspondence: chiara.gasparini@asst-fbf-sacco.it

'Department of Pediatrics, Vittore Buzzi Children's Hospital, University of Milan, Via Castelvetro 32, 20154 Milan, Italy

Full list of author information is available at the end of the article
}

(c) The Author(s). 2021 Open Access This article is licensed under a Creative Commons Attribution 4.0 International License, which permits use, sharing, adaptation, distribution and reproduction in any medium or format, as long as you give appropriate credit to the original author(s) and the source, provide a link to the Creative Commons licence, and indicate if changes were made. The images or other third party material in this article are included in the article's Creative Commons licence, unless indicated otherwise in a credit line to the material. If material is not included in the article's Creative Commons licence and your intended use is not permitted by statutory regulation or exceeds the permitted use, you will need to obtain permission directly from the copyright holder. To view a copy of this licence, visit http://creativecommons.org/licenses/by/4.0/ The Creative Commons Public Domain Dedication waiver (http://creativecommons.org/publicdomain/zero/1.0/) applies to the data made available in this article, unless otherwise stated in a credit line to the data. 
Conclusion: (Fluenz Tetra ${ }^{\mathrm{TM}}$ ) proved to be easy to administer and the degree of satisfaction was high among both health workers and parents. Considering its substantial safety profile especially in school-age children and adolescents, all these aspects make the nasal qLAIV optimal for widespread immunization.

Schools offer the best setting to reach more families and physicians should be actively involved.

Keywords: Influenza, Widespread immunization, Quadrivalent live attenuated influenza vaccine, Children, Adverse events

\section{Background}

Influenza virus is responsible for nearly $30 \%$ of the infectious disease burden in Europe: every year up to 50 million people contract symptomatic flu and the high number of mild to moderate infections leads to loss in production and pressure on health services $[1,2]$. In Italy the average annual frequency of influenza cases in the general population is estimated around $9 \%$. In the age group $0-14$, which is the most affected, the incidence is around $26 \%(12-40 \%)$ [3].

The purpose of a vaccination programme for all children is to provide them with direct protection, thereby creating indirect protection to the adult population, since children are the major propagators of influenza [4, 5] and represent a crucial reservoir of the virus [6-9].

Live attenuated influenza vaccine (LAIV) is approved for use in Europe [10], US [11] and Canada [12]. Fluenz Tetra $^{\text {Tx }}$, in particular, is a non-invasive intranasal quadrivalent LAIV (qLAIV) used in children and adolescents aged 2 to 17 years. A recent comparative study of LAIV vs inactivated influenza vaccine (IIV) concluded that LAIV is more effective in preventing influenza in children $[4,13]$ and one of its advantages is the capacity to induce immune responses at the site of infection [14]. The most common adverse event reported after LAIV administration was nasal congestion [15]. A large phase III trial with LAIV recorded an increased incidence of medically significant wheezing in vaccine-naive children aged less than 24 months and an increase of hospitalizations in children aged 6-11 months as compared with the trivalent inactivated vaccine (TIV). Belshe RB et al. concluded that LAIV was highly effective and safe for children aged 12 through 59 months with no previous history of asthma or wheezing [16]. In the UK a universal childhood vaccine programme with LAIV was introduced in 2012 [15] and in 2018/19 flu season it was estimated that the overall adjusted vaccine effectiveness for 2 to 17 years olds receiving LAIV was 48.6\% [17].

In Italy the coverage in children and adolescents has always been very low, reaching a peak of $4.2 \%$ in children aged 2 to 4 and a minimum of $1.9 \%$ of the $9-17$ population (2019/20 flu season) [18].

For the 2020/21 season, flu vaccination has been extended to all children aged 6 months through 6 years and the Lombardy region chose to introduce Fluenz
Tetra $^{\text {m }}$ for the first time in Italy, in addition to the IIV (Vaxigrip Tetra ${ }^{\circ}$ ) [19]. (Fluenz Tetra ${ }^{\mathrm{Tm}}$ ) was administered by nurses, health care assistants, medical specialists and resident physicians in various vaccination centres in Milan.

The primary outcome of the study was to assess the number of adverse reactions, their severity, and the possible presence of factors influencing them. Demographic data of vaccinated children and their families were collected in order to evaluate uniformity of access to care. Finally, the degree of satisfaction with the vaccination and the intention to repeat it in the following year for both parents and health care providers was measured, with the aim of identifying factors that could help planning the 2021-22 vaccination campaign.

\section{Materials and methods Study design}

This observational study was conducted in Milan by the Pediatric University Department of the Buzzi Children's Hospital together with the District Social Health Fatebenefratelli-Sacco during the 2020-21 influenza vaccination campaign. In the six vaccination centres in the city a total of 9292 children received the (Fluenz Tetra ${ }^{\mathrm{m}}$ ) vaccine: 7675 in the 2 to 6 age group and 1617 in the 7 to 17 one.

\section{Questionnaires}

A questionnaire was given out to parents on the day of the vaccination, on a voluntary and anonymous basis, through which information about children and their parents was collected, guaranteeing privacy. (Table 1) The data included demographic info on the child (gender, date and place of birth, gestational age at birth, presence of siblings, day care attendance) and his parents (date of birth, place of birth, level of education) and for both, whether they had been vaccinated in the 2019-20 season. For the children we collected data on previous acute infectious diseases in 2020 prior to vaccination, for both children and parents we gathered information on possible chronic diseases. They were also asked why and how they became aware of the influenza vaccination.

Between one and 3 months later, the parents were contacted by phone to check if there had been any adverse reactions following (Fluenz Tetra ${ }^{\mathrm{mi}}$ ) administration. 
Table 1 Questionnaire for parents on vaccination day

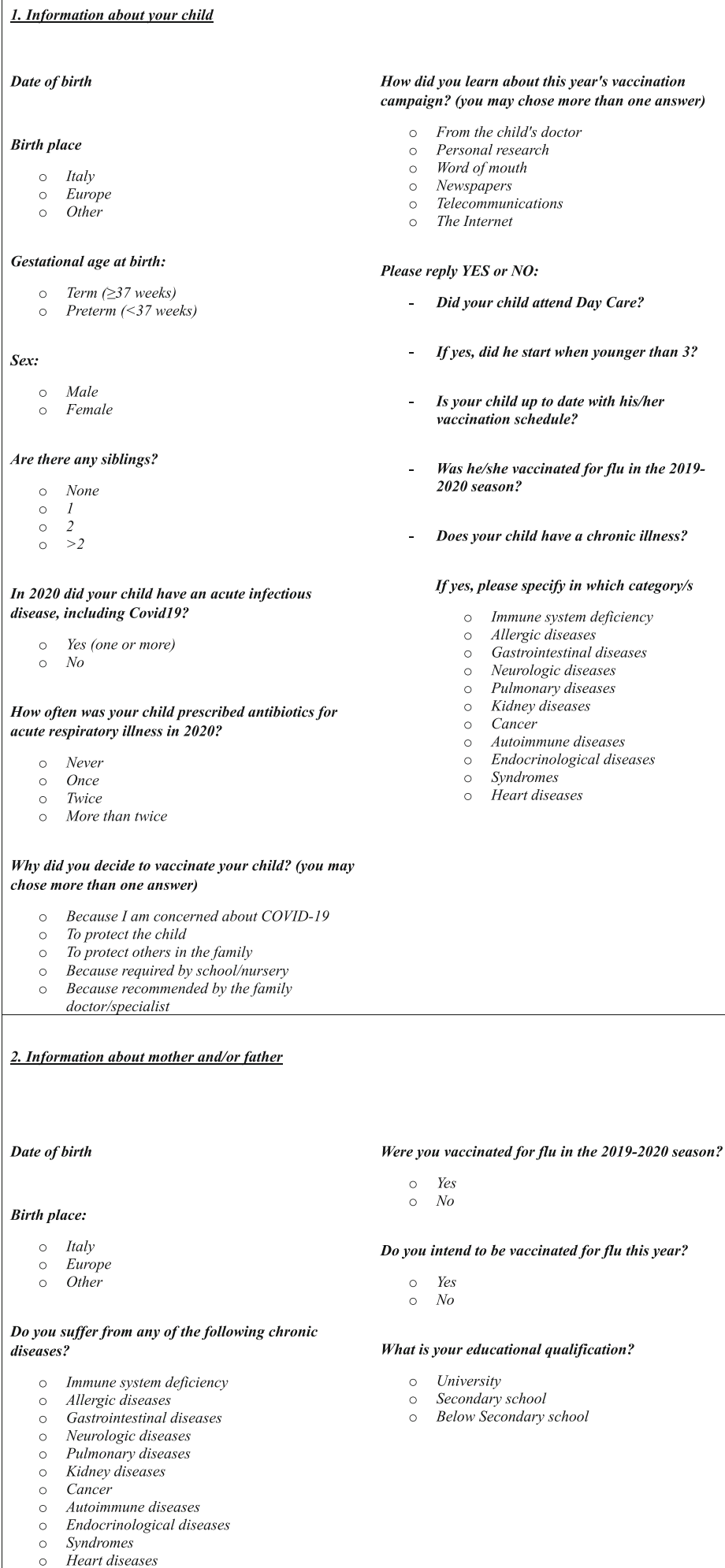

Date of birth

Birth place

- Italy

- Europe

- Other

Gestational age at birth:

- $\operatorname{Term}(\geq 37$ weeks $)$

- Preterm $(<37$ weeks $)$

Sex:

- Male

Female

Are there any siblings?

- None

$\circ \quad 1$

$\stackrel{2}{>2}$

In 2020 did your child have an acute infectious disease, including Covid19?

- Yes (one or more)

No

How often was your child prescribed antibiotics for acute respiratory illness in 2020?

- Never

Once

More than twice

Why did you decide to vaccinate your child? (you may

chose more than one answer)

Because I am concerned about COVID-19

To protect the child

To protect the child

To protect others in the family
Because required by school/nursery

Because required by school/nursery
Because recommended by the family

doctor/specialist

2. Information about mother and/or father

Date of birth

Were you vaccinated for flu in the 2019-2020 season?

- Yes

Birth place:

Italy

Europe

Do you intend to be vaccinated for flu this year?

$\therefore \quad$ Yes

Do you suffer from any of the following chronic diseases?

Immune system deficiency

Allergic diseases

Gastrointestinal diseases

Neurologic diseases

Pulmonary diseases

Kidney diseases

Cancer

Autoimmune diseases

Endocrinological diseases

Syndromes

Syndromes
Heart diseases

wourn about this year's vaccination

From the child's doctor

Personal research

Word of mouth

Telecommunications

The Internet

Please reply YES or NO:

- Did your child attend Day Care?

- If yes, did he start when younger than 3 ?

Is your child up to date with his/her vaccination schedule?

Was he/she vaccinated for flu in the 2019 2020 season?

Does your child have a chronic illness?

If yes, please specify in which category/s

Immune system deficiency

Allergic diseases

Gastrointestinal diseases

Neurologic diseases

Pulmonary diseases

Kidney diseases

Autoimmune diseases

Endocrinological diseases

Syndromes

Heart diseases

What is your educational qualification?

- University

- Secondary school

- Below Secondary school 
We asked if there were any immediate reactions, within $4 \mathrm{~h}$, and/or late reactions and whether hospitalization had occurred within 1 week of vaccination. Adverse reactions included a cold, decreased appetite, headache, muscle aches, fever, nosebleed, cough/wheezing, malaise, hives, skin rash, vomiting/diarrhoea, other.

Parents were asked to judge the intensity of each adverse reaction: mild if lasting less than 3 days and not interfering with the child's normal activities, moderate when lasting less than 3 days but altering everyday life, significant if lasting $\geq 3$ days and /or requesting medical attention.

Fever was defined as mild if body temperature was > $37.4{ }^{\circ} \mathrm{C}$ and $\leq 38^{\circ} \mathrm{C}$, moderate if $>38^{\circ} \mathrm{C}$ and $\leq 38.9^{\circ} \mathrm{C}$ and significant if $\mathrm{T}>38.9^{\circ} \mathrm{C}$.

They were also asked if they were satisfied with the vaccination (very/enough/not satisfied) and whether they intended to join the following year's campaign (yes/no/ don't know).

Finally, a questionnaire was sent by e-mail to all health workers to be filled in electronically on a Google form collecting demographic data, previous vaccination experience, rating of the administration of the (Fluenz Tetra $^{\mathrm{TM}}$ ), overall rating of the experience and intention to repeat it the following year. (Table 2).

\section{Statistical analysis}

Characteristics of children and their parents are described using numbers and percentages. Missing data are excluded when computing percentages.
To compare the way in which the parents became aware of the vaccination campaign in children with or without chronic diseases, Fisher exact test was computed and $p$-values were provided.

To further evaluate the adverse reactions to vaccination, the percentages of children with adverse reactions are computed according to age, sex, presence of acute infectious diseases in 2020, chronic diseases, allergic diseases, flu vaccine in 2019. Moreover, a multiple logistic regression model is fitted using binomial family and link log, where the response variable is the presence of adverse reactions and the exploratory variables are the children's characteristics previously cited.

To investigate the attitude of people towards future immunization, the percentage of children whose parents didn't want to repeat the vaccination next year (or are doubtful) is computed according to the children's and parents' characteristics and a marginal multiple logistic regression model is fitted using binomial family and link $\log$, where the response variable is the choice of not repeating the vaccination (or being doubtful) and the exploratory variables are the children's and parents' characteristics and the correlation of measures among the same family is taken into account. The results of all the multiple logistic regression models are reported, for each explanatory variable, in terms of adjusted Risk Ratio (aRR) computed with respect to a reference category, together with $95 \%$ confidence interval and $p$ value of Wald test.

All analyses were performed using $\mathrm{R}$ software version 4.0.5, with geepack package added.

Table 2 Questionnaire for health workers

\begin{tabular}{|c|c|}
\hline Date of birth & 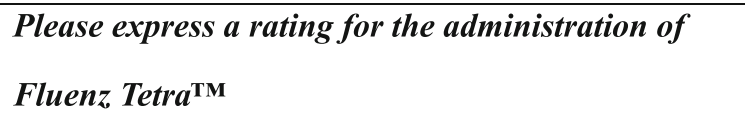 \\
\hline $\begin{array}{l}\text { Gender: } \\
\qquad \begin{aligned} \\
\circ \quad \text { Male } \\
\circ \quad \text { Female }\end{aligned}\end{array}$ & $\begin{array}{ll}\circ & \text { Easy } \\
\circ & \text { Normal } \\
\circ & \text { Difficult }\end{array}$ \\
\hline $\begin{array}{l}\text { Occupation: } \\
\qquad \begin{aligned} \circ & \text { Health care assistant } \\
\circ & \text { Medical specialist } \\
\circ & \text { Resident physician } \\
\circ & \text { Nurse }\end{aligned}\end{array}$ & $\begin{array}{l}\text { Please express an overall rating of the experience } \\
\qquad \text { Bad } \\
\circ \text { Good } \\
\circ \text { Very good } \\
\text { Would you repeat nasal spray vaccination next year? }\end{array}$ \\
\hline $\begin{array}{l}\text { Previous vaccination experience: } \\
\qquad \begin{aligned} \circ & \text { None } \\
\circ & \text { Occasional } \\
\circ & \text { Routine }\end{aligned}\end{array}$ & $\begin{array}{ll}\circ & \text { Yes } \\
\circ & \text { No } \\
\circ & \text { Don't know }\end{array}$ \\
\hline
\end{tabular}




\section{Results}

\section{Demographic and health data}

A total of 7074 questionnaires were collected; of these 600 were null, as no telephone number was provided.

A sample of these questionnaires $(n=3571)$ was selected for telephone follow-up. We received a response from 2152 families, obtaining information about 3226 children, aged 2 to 17, equally distributed between males and females (52\% vs $48 \%)$, considering many had siblings.

The population was divided into 3 age groups: $59.8 \%$ preschoolers (2-5 years), $36.6 \%$ primary school-age children (6-10 years) and $3.6 \%$ adolescents (11-17 years).

The children and adolescents who participated in the study were mostly healthy $(94.3 \%)$, born at term $(88.7 \%)$, up to date with the vaccination schedule (99.7\%) and not vaccinated for influenza in the year 2019-20 (82.4\%). Among the subjects with chronic illness $(5.7 \%$ of the total) 101 were affected by allergic disease (55\%) and 27 by lung diseases (14.7\%). The remaining 30.3\% were equally distributed among gastroenterological, neurological, kidney, autoimmune, endocrinological and heart diseases, syndromes and cancer.

Half of the study population (52.5\%) reported at least one acute infectious disease in 2020, before the vaccination took place, for most of which $(75.8 \%)$ antibiotics were not prescribed.

Almost all children and adolescents were born in Italy (97.6\%) to an Italian mother $(86.3 \%)$ and an Italian father $(90 \%)$; most of them had at least one brother or sister $(80.7 \%)$.

The demographic and health characteristics of the study population are shown in Table 3.

We also evaluated the demographic data of the parents: the average age was 38 for the mothers and 42 for the fathers; both were mostly healthy $(75.8 \%$ of mothers and $83.3 \%$ of fathers) and only a minority received the flu vaccine in previous years $(29.4 \%$ of mothers and $23 \%$ of fathers), while $54.4 \%$ of the mothers and $46.3 \%$ of the fathers expressed their intention to be vaccinated in the current season.

We considered the level of education of the parents: most of them (75\% of mothers and $64 \%$ of fathers) had a university degree, followed by $21 \%$ of mothers and $29 \%$ of fathers with secondary school diploma, while the remaining ( 4 and $7 \%$ respectively) completed primary education.

Data is shown in Table 4.

\section{Questionnaire}

We investigated the reasons why parents vaccinated themselves and their children and how they became aware of the vaccination campaign.
Most families chose to vaccinate their children "to protect" them (54.6\%), and "because they were concerned about Covid19" (44.9\%), others "because recommended by the family doctor or specialist" (39.1\%), and "to protect other members of the family" (26.7\%).

The main way in which parents became aware of a new flu vaccination was word-of-mouth (39.8\%), which occurred mostly among parents of the same school group, followed by information from the child's doctor (30.6\%), the Internet (26.9\%), personal research (15\%), newspapers $(4 \%)$, telecommunications $(7.5 \%)$ and other (2.6\%).

In particular, it appears that the role of medical opinion was prevalent among parents with primary education (37\%), while word of mouth among parents with university education (40.7\%).

On the other hand, if we analyse the way in which the parents became aware of the vaccination campaign by comparing children with or without chronic diseases, it emerges that the role of the child's physician was determining in those with chronic diseases (50\%) compared to healthy children (30\%), $p$-value of Fisher exact test $=$ 0.003 . Word of mouth prevailed instead among children without chronic diseases $(40.2 \%)$ compared to children with chronic diseases (26.8\%), $p$-value of Fisher exact test $=0.052$.

\section{Follow up 1 to 3 months post vaccination with (Fluenz tetra $\left.^{\mathrm{TM}}\right)$ : adverse events}

During the telephone interviews, $1-3$ months after vaccination, one or more adverse events were reported in 801 children (in total 24.8, 26.7\% in females, $23.1 \%$ in males) adding up to 1039 adverse events, of which 837 were mild (80.6\%), 188 moderate (18.1\%), and 13 significant $(1.3 \%)$ as shown in Table 5.

The most common symptom was a cold with 545 events (52.5\%), followed by fever with 254 reports (24.4\%) and malaise in 97 cases (9.3\%).

The 13 significant reactions were intense rhinitis $(n=$ $7)$, high fever $(n=2)$, prolonged decreased appetite $(n=$ $1)$, intense headache $(n=1)$, hives $(n=1)$, perforated otitis $(n=1)$. Moreover, one child was hospitalized for cough and respiratory difficulty 3 days after the vaccination: the final diagnosis, however, was found to be pneumonia due to Mycoplasma Pneumoniae.

On the other hand, no immediate adverse reactions occurred.

Table 6 shows the adverse effects divided by age, sex, acute infectious diseases in 2020, chronic or allergic diseases and flu shot in the 2019-20 season.

The statistical analysis of adverse reactions, performed with the multiple regression model, showed that children aged 2-5 have an increased risk of adverse events if compared with both the 6-10 years age group (aRR 1.7, 
Table 3 demographic and health characteristics of the children

\begin{tabular}{|c|c|}
\hline & $\begin{array}{l}\text { CHILDREN }(N=3226) \\
\mathrm{n}(\%)\end{array}$ \\
\hline \multicolumn{2}{|l|}{ Age } \\
\hline Preschoolers ( $2-5$ years old) & $1924(59.8)$ \\
\hline Schoolers (6-10 years old) & $1179(36.6)$ \\
\hline Adolescents ( $11-17$ years old) & $116(3.6)$ \\
\hline \multicolumn{2}{|l|}{ Sex } \\
\hline Female & $1546(47.9)$ \\
\hline Male & $1680(52.1)$ \\
\hline \multicolumn{2}{|l|}{ Place of birth } \\
\hline Italy & $3149(97.6)$ \\
\hline Europe & $33(1)$ \\
\hline Other & $44(1.4)$ \\
\hline \multicolumn{2}{|l|}{ Gestational age at birth } \\
\hline Term & $2855(88.7)$ \\
\hline Preterm & $365(11.3)$ \\
\hline \multicolumn{2}{|l|}{ Siblings } \\
\hline None & $623(19.3)$ \\
\hline 1 & $2019(62.6)$ \\
\hline 2 & $471(14.6)$ \\
\hline$>2$ & $113(3.5)$ \\
\hline \multicolumn{2}{|l|}{ Daycare attendance } \\
\hline No & $322(10)$ \\
\hline Before age 3 & $2870(90)$ \\
\hline Up to date with the vaccination schedule & $3217(99.7)$ \\
\hline Influenza vaccine in 2019-2020 season & $569(17.6)$ \\
\hline Chronic diseases & $184(5.7)$ \\
\hline Immune system deficiency & - \\
\hline Allergic diseases & $101(3.13)$ \\
\hline Gastrointestinal diseases & $4(0.12)$ \\
\hline Neurologic diseases & $13(0.4)$ \\
\hline Pulmonary diseases & $27(0.84)$ \\
\hline Kidney diseases & $12(0.37)$ \\
\hline Cancer & $3(0.09)$ \\
\hline Autoimmune diseases & $8(0.25)$ \\
\hline Endocrinological diseases & $6(0.19)$ \\
\hline Syndromes & $3(0.09)$ \\
\hline Heart diseases & $7(0.22)$ \\
\hline \multicolumn{2}{|l|}{ Acute infectious disease in 2020} \\
\hline No & $1531(47.5)$ \\
\hline One or more & $1695(52.5)$ \\
\hline \multicolumn{2}{|l|}{ Antibiotic therapy during 2020} \\
\hline No & $2447(75.8)$ \\
\hline Once & $628(19.5)$ \\
\hline Twice & $116(3.6)$ \\
\hline More than twice & $35(1.1)$ \\
\hline
\end{tabular}


Table 4 demographic and health characteristics of the parents

\begin{tabular}{|c|c|c|}
\hline & $\begin{array}{l}\text { MOTHERS (N: 2142) } \\
\text { n (\%) }\end{array}$ & $\begin{array}{l}\text { FATHERS (N:2115) } \\
\text { n (\%) }\end{array}$ \\
\hline \multicolumn{3}{|l|}{ Age (years) } \\
\hline $20-29$ & $51(2.4)$ & $22(1)$ \\
\hline $30-39$ & $937(44.2)$ & $627(30)$ \\
\hline $40-49$ & $1072(50.5)$ & $1225(58.6)$ \\
\hline$\geq 50$ & $61(2.9)$ & $217(10.4)$ \\
\hline \multicolumn{3}{|l|}{ Place of birth } \\
\hline Italy & $1848(86.3)$ & $1903(90)$ \\
\hline Europe & $81(3.8)$ & $47(2.2)$ \\
\hline Other & $213(9.9)$ & $164(7.8)$ \\
\hline \multicolumn{3}{|l|}{ Level of education } \\
\hline University & $1608(75)$ & $1355(64)$ \\
\hline Secondary school & $444(21)$ & $612(29)$ \\
\hline Below Secondary school & $88(4)$ & $148(7)$ \\
\hline \multicolumn{3}{|l|}{ Chronic diseases } \\
\hline Immunodeficiencies & $10(0.46)$ & $7(0.32)$ \\
\hline Allergic diseases & $236(10.96)$ & $210(9.75)$ \\
\hline Gastrointestinal diseases & $35(1.62)$ & $25(1.2)$ \\
\hline Chronic infectious diseases & $2(0.09)$ & - \\
\hline Neurologic diseases & $13(0.6)$ & $7(0.3)$ \\
\hline Pulmonary diseases & $15(0.71)$ & $8(0.4)$ \\
\hline Kidney diseases & $9(0.42)$ & $8(0.4)$ \\
\hline Cancers & $31(1.44)$ & $24(1.1)$ \\
\hline Autoimmune diseases & $65(3.02)$ & $24(1.1)$ \\
\hline Endocrinological diseases & $84(3.9)$ & $10(0.5)$ \\
\hline Syndromes & $4(0.19)$ & $3(0.1)$ \\
\hline Heart diseases & $18(0.84)$ & $34(1.6)$ \\
\hline Flu vaccination in $2019-2020$ season & $633(29.4)$ & $496(23)$ \\
\hline Flu vaccination in $2020-2021$ season & $1172(54.4)$ & $997(46.3)$ \\
\hline
\end{tabular}

95\% CI 1.5-1.9, $p<0.001)$ and the $11-17$ years old one (aRR 1.5, 95\% CI 1-2.2, $p=0.051$ ). The same was observed in children who had at least 1 acute infectious disease in 2020 as compared with not having had any (aRR 1.2, 95\% CI 1.1-1.4, $p=0.004$ ), or suffering from a chronic disease compared with not being affected (aRR 1.6, 95\% CI 1.2-2.1, $p=0.001)$.

On the other hand, there is a decrease in the probability of having adverse reactions in males compared to females (aRR 0.9, 95\% CI 0.8-1, $p=0.011$ ).

Children aged 6-10 and adolescents share the same risk of presenting an adverse event (aRR 0.9, 95\% CI $0.6-1.4, p=0.584)$, similarly allergic versus healthy subjects (aRR 1.1, 95\% CI 0.7-1.5, $p=0.667$ ), and vaccinated with influenza in 2019 compared to not vaccinated (aRR $0.9,95 \%$ CI $0.8-1.1, p=0.382$ ).
When we considered the preschool age group (2-5 years old), the percentage of adverse events was similar in children born at term (29.9\%) and preterm (26.6\%). So prematurity is neither a risk nor a protective factor compared with being born at term (aRR 0.9, 95\% CI $0.7-1.1, p=0.220$ ).

\section{Parent's satisfaction and intention to repeat}

Between 1 and 3 months after vaccination, we evaluated the degree of satisfaction of the (Fluenz Tetra $^{\mathrm{Ts}}$ ) vaccine and the intention to repeat it the following year.

Most parents (83.3\%) were very satisfied, $15.2 \%$ satisfied enough, $1 \%$ not satisfied.

Most parents $(83.8 \%)$ would be happy to re-vaccinate their children with the nasal spray qLAIV during the 
Table $\mathbf{5}$ adverse events

\begin{tabular}{|c|c|c|c|c|}
\hline & $\begin{array}{l}\text { Mild } \\
\mathrm{n}\end{array}$ & $\begin{array}{l}\text { Moderate } \\
\mathrm{n}\end{array}$ & $\begin{array}{l}\text { Significant } \\
\mathrm{n}\end{array}$ & $\begin{array}{l}\text { TOTAL } \\
\text { n (\%) }\end{array}$ \\
\hline Cold & 424 & 114 & 7 & $545(52.5)$ \\
\hline Decreased appetite & 22 & 1 & 1 & $24(2.3)$ \\
\hline Headache & 45 & 4 & 1 & $50(4.8)$ \\
\hline Muscle aches & 7 & 3 & - & $10(0.9)$ \\
\hline Fever & 208 & 44 & 2 & $254(24.5)$ \\
\hline Nosebleed & 4 & 2 & - & $6(0.6)$ \\
\hline Cough/wheezing & 17 & 7 & - & $24(2.3)$ \\
\hline Asthma & - & - & - & - \\
\hline Malaise & 91 & 6 & - & $97(9.3)$ \\
\hline Hives & 1 & - & - & $1(0.1)$ \\
\hline Skin rash & 8 & 3 & 1 & $12(1.2)$ \\
\hline Vomiting and/or diarrhoea & 10 & 2 & - & $12(1.2)$ \\
\hline Otitis & - & 1 & 1 & $2(0.2)$ \\
\hline Angioedema & - & 1 & - & $1(0.1)$ \\
\hline TOTAL n (\%) & 837 (80.6) & $188(18.1)$ & $13(1.3)$ & 1038 \\
\hline
\end{tabular}

next flu campaign, $15.3 \%$ do not know if they would repeat the vaccination and $0.9 \%$ do not intend to repeat it.

We assessed the impact of the following factors on the intention to repeat (Fluenz Tetra $^{\mathrm{Tm}}$ ) vaccination next year: adverse reactions, the main reasons that led parents to request vaccination ("to protect their son/daughter" and "because they were concerned about Covid19"), the degree of satisfaction and whether the parents had previously been vaccinated for influenza.

Vaccinating the child for its personal protection (aRR $1,1,95 \%$ CI $1-1,1, p<0.001)$ and parental vaccination

Table 6 percentage of children with adverse events according to characteristics

\begin{tabular}{ll}
\hline Categories & $\%$ \\
\hline Preschoolers & 29.5 \\
Primary school & 17.6 \\
Adolescents & 19.0 \\
Female & 26.7 \\
Male & 23.1 \\
Children without acute infectious disease in 2020 & 21.6 \\
Children with at least 1 acute infectious disease in 2020 & 78.4 \\
Children without chronic illness (allergies excluded) & 24.5 \\
Children with at least 1 chronic illness (allergies excluded) & 37.5 \\
Children without allergic disease & 24.8 \\
Children with allergic disease & 24.8 \\
Children not vaccinated against influenza in 2019 & 25.0 \\
Children vaccinated against influenza in 2019 & 24.1 \\
\hline
\end{tabular}

are both strongly associated with the intention to repeat the flu vaccine the following year (aRR 1,5, 95\% CI 1,2$1,7, p<0,001$ ).

The decision to vaccinate because "worried about Covid19" makes families undecided whether to repeat the vaccine in the next season (aRR 1,5, 95\% CI 1,2-1,7, $p<0,001)$.

Adverse reactions were the main reason not to repeat the vaccination for the few parents who declared this decision (aRR 5.5, 95\% CI 2.4-12.5, $\mathrm{p}<0,001$ ).

\section{Health workers satisfaction questionnaire}

Fifty-six health workers, average age 40, mostly women (73.2\%), responded to the satisfaction questionnaire. Most of them were resident physicians (55.4\%), followed by nurses (25\%), medical specialists $(17.9 \%)$ and one health care assistant (1.8\%). Twenty-two of them (39.3\%) stated that they routinely performed vaccinations, 19 (33.9\%) that they performed them occasionally and 15 $(26.8 \%)$ that they had no previous vaccination experience.

Their opinion on the administration of the nasal spray was collected: $60.7 \%$ found it easy, 37.5\% normal and only one (1.8\%) difficult.

Finally, we evaluated the overall satisfaction of the operators regarding the vaccination experience with (Fluenz Tetra ${ }^{\mathrm{Tx}}$ ) and their willingness to join an influenza campaign with a nasal spray vaccine again. Most operators (93\%) described the experience as excellent, $5.3 \%$ as good and one (1.8\%) as bad. Fifty-three of 56 (94.6\%) 
would be available to use this type of vaccine again, whereas $5.4 \%$ did not know (Table 7).

\section{Discussion}

This survey confirms the safety of qLAIV (Fluenz Tetra $^{\text {tix }}$ ) administered to children and adolescents aged 2 to 17 years, considering both the type and the severity of the adverse events observed [15].

In fact in our study rhinitis was the most common side effect, followed by fever and malaise; on the other hand, in contrast to reports in other similar studies [15, 20], in our population cough and respiratory distress were not relevant. No immediate adverse reactions were documented.

As reported in literature [15], in the week following vaccination, most of the side effects we observed proved to be mild to moderate in severity. Moreover, the small number of subjects enrolled in our study that experienced significant adverse events didn't require hospitalization and none reported delayed adverse reactions.

Table 7 health workers survey

\begin{tabular}{lc}
\hline & $\begin{array}{c}\text { HEALTH WORKERS (N: 56) } \\
\mathbf{n}(\%)\end{array}$ \\
\hline Gender & $41(73.2)$ \\
Female & $15(26.8)$ \\
Male & \\
Occupation & $1(1.8)$ \\
Health care assistant & $10(17.9)$ \\
Medical specialist & $31(55.4)$ \\
Resident physician & $14(25)$ \\
Nurse & \\
Previous vaccination experience & $15(26.8)$ \\
None & $19(33.9)$ \\
Occasional & $22(39.3)$ \\
Routine & $32(93)$ \\
Rating of administration of (Fluenz Tetra & \\
Easy & $34(60.7)$ \\
Normal & $21(37.5)$ \\
Difficult & $1(1.8)$ \\
Overall rating of the experience & \\
Bad & \\
Good & \\
Very good & \\
Yestion to vaccinate the following year & \\
No & \\
Don't know & $(5.7)$ \\
\hline & \\
\hline
\end{tabular}

As we expected, children aged 2-5 years, being closer to the (Fluenz Tetra ${ }^{\mathrm{Tm}}$ ) utilization age limit, had the majority of adverse events, whereas the risk of developing side effects decreased nearly two-fold in children aged 6-11+ years and adolescents. These data show intranasal qLAIV is particularly well tolerated by the latter.

Our study also showed that besides preschoolers, those with chronic diseases excluding allergies, and those who had at least one acute infectious disease in the previous year, experienced a significantly higher risk of developing side effects. On the other hand prematurity was not associated with a higher frequency of side effects.

We were pleased to observe that allergies, which represent the most common chronic disease in childhood, did not increase the risk of adverse events. To be noted that children with severe asthma or anaphylaxis to egg proteins did not receive qLAIV, according to AIFA's indication and (Fluenz Tetra ${ }^{\mathrm{at}}$ ) leaflet [21].

We also collected interesting information from the questionnaires that lead to important considerations that will help program the vaccination campaigns in Italy in the years to come.

For instance, while the proportion of foreign parents was in line with the foreign population in Milan $(11.9 \%$ vs $14.1 \%$ ) [22], other factors were peculiar to our study population. In particular we had a very high proportion of parents with university degrees compared to the Italian population $(69.6 \%$ vs $28 \%)$ [23]; we had a high percentage of parents who were vaccinated themselves (26.2\% compared to $2.2 \%$ of all subjects aged $18-44$ in the Lombardy region in 2019-20) [18]; and finally a very high proportion of children that had attended day care before the age of three $(90 \%$ in our study compared to $30 \%$ of children in the North of Italy, with a peak of $47 \%$ in children of parents with higher education) [24].

These data lead us to believe that the 2020-21 influenza vaccination campaign failed to reach all sections of the population, and that those with a higher education and with established knowledge regarding vaccination were favoured.

Parents interviewed affirmed that they learned about the vaccination campaign through word of mouth, consisting of informal social media communications among parents of the same school group. The school therefore played an important role, not so much as an institution, as through its social role. Interestingly, the school has been mentioned in several studies as a possible place to check the immunization status and promote educational programmes for families [25].

Although in several studies health professionals are considered the most important source of information for parents, influencing the decision to vaccinate their children or not $[26,27]$, only $30 \%$ of the parents interviewed declared that they had heard about the vaccination 
campaign through their doctor, but this percentage increases to $50 \%$ if we consider parents of children with chronic diseases. In the latter, the role of the physician was decisive in the parents' choice to have their children vaccinated against influenza.

Despite the ongoing Covid19 pandemic, most parents chose to vaccinate their children "to protect them", indicating that they had grasped the real indication for flu vaccination and wanted to take advantage of the opportunity offered, this year for the first time, to vaccinate healthy children and young people free of charge with an easy-to-administer vaccine. The decision to vaccinate for this particular reason, as well as the decision by parents to undergo flu vaccination themselves, is associated with a stronger desire to repeat the vaccination next year, as reported in literature [28].

Instead, having their children vaccinated because "they were concerned about Covid19", which was the second most frequent reason given by parents, makes families hesitant about reconfirming the vaccination next year.

Adverse reactions, however, were the main factor influencing parents' decision not to repeat the vaccine.

(Fluenz $\operatorname{Tetra}^{\mathrm{Tm}}$ ) proved to be non-invasive, easy and practical to administer even for inexperienced operators, such as most of those who took part in this flu campaign. This entailed that the degree of satisfaction was high among both health workers and parents, with the former mostly willing to repeat the experience in future years, and the latter mostly intending to have their children vaccinated again.

The study conducted leads us to conclude that the substantial safety of the vaccine, especially in school-age children and adolescents, the ease of administration and the high level of acceptance by families make the nasal qLAIV suitable for widespread vaccination of these subjects.

We therefore believe that it is important to inform and involve families extensively, especially through the school setting, and that it is desirable for physicians to be actively involved in the vaccination education of their patients.

\section{Abbreviations}

IIV: Inactivated influenza vaccine; LAIV: Live attenuated influenza vaccine; qLAIV: Quadrivalent live attenuated influenza vaccine

\section{Acknowledgements}

We would like to thank all the families who, through the Buzzi Foundation, have allowed the creation of new vaccination stations. We would also like to thank all the staff who participated in the vaccination campaign, in particular the resident physicians of the University of Milan.

\section{Authors' contributions}

GVZ, CG and CRB made substantial contributions to the design of the study. $C G, C R B$ and $C B$ contributed greatly with the logistics concerning data acquisition. $M A, A B, F M$ and $S R$ created the database and data acquisition system. $A O$ and $P B$ provided statistical model and relevant numerical evaluation. GVZ, CG, MRA, AO, PB, contributed with the analysis and interpretation of data. CG, MRA, MA, AB, FM and SR drafted the work. GVZ, $C G, C R B, C B, A O, P B$ and MRA substantively revised the article and the relevant conclusion. All authors have approved the submitted version.

\section{Funding}

Not applicable.

\section{Availability of data and materials}

Most important elaborated data generated and analysed during the study are included in this published article. Raw data will be available on request at V. Buzzi Ospital contact Dr. Chiara Gasparini (chiara.gasparini@asst-fbfsacco.it; phone + 39.02.6363.5331)

\section{Declarations}

Ethics approval and consent to participate

No ethical approval is required for this study according to the regional law of the Lombardia Region number 3 of the year 2012

\section{Consent for publication}

Not applicable.

\section{Competing interests}

The authors declare that they have no known competing financial interests or personal relationships that could have appeared to influence the work reported in this paper.

\section{Author details}

${ }^{1}$ Department of Pediatrics, Vittore Buzzi Children's Hospital, University of Milan, Via Castelvetro 32, 20154 Milan, Italy. ${ }^{2}$ Vaccination Unit, ASST Fatebenefratelli Sacco, Milan, Italy. ${ }^{3}$ Primary Care, ATS, Pavia, Italy.

${ }^{4}$ Department of Clinical Sciences and Community Health, Laboratory of Medical Statistics, Epidemiology and Biometry "G. A. Maccacaro", University of Milan, Milan, Italy.

Received: 19 July 2021 Accepted: 20 October 2021

Published online: 13 November 2021

\section{References}

1. European Centre for Disease Prevention and Control (ECDC). Factsheet about seasonal influenza. Available at the website: https://www.ecdc.europa. eu/en/seasonal-influenza/facts/factsheet. Accessed 10 Apr 2021.

2. European Centre for Disease Prevention and Control (ECDC). Seasonal influenza vaccination and antiviral use in EU/EEA Member States - Overview of vaccine recommendations for 2017-2018 and vaccination coverage rates for 2015-2016 and 2016-2017 influenza seasons. Stockholm: ECDC; 2018. Available at the website: https://www.ecdc.europa.eu/sites/default/files/ documents/seasonal-influenza-antiviral-use-2018.pdf. Accessed 10 Apr 2021.

3. Istituto Superiore di Sanità (ISS) - EpiCentro. Influenza - Informazioni generali. Available at the website: https://www.epicentro.iss.it/influenza/ influenza. Accessed 10 Apr 2021.

4. Smith KJ, Raviotta JM, DePasse JV, Brown ST, Shim E, Patricia Nowalk M, et al. Cost effectiveness of influenza vaccine choices in children aged 2-8 years in the U.S. Am J Prev Med. 2016;50(5):600-8. https://doi.org/10.1016/j.a mepre.2015.12.010.

5. Gregg M, Blackhouse G, Loeb M, Goeree R. Economic evaluation of an influenza immunization strategy of healthy children. Int J Technol Assess Health Care. 2014;30(4):394-9. https://doi.org/10.1017/S0266462314000397.

6. Pebody RG, Green HK, Andrews N, Boddington NL, Zhao H, Yonova I, et al. Uptake and impact of vaccinating school age children against influenza during a season with circulation of drifted influenza a and B strains, England, 2014/15. Eurosurveillance. 2015;20:39. https://doi.org/10.2807/15607917.ES.2015.20.39.30029.

7. Grijalva CG, Zhu Y, Simonsen L, Mitchel E, Griffin MR. The Population Impact of a Large School-Based Influenza Vaccination Campaign. Poon LLM, editor. PLoS One. 2010;5(11):e15097.

8. King JC. A pilot study of the effectiveness of a school-based influenza vaccination program. Pediatrics. 2005;116(6):e868-73. https://doi.org/10.1 542/peds.2005-1301.

9. King JC, Lichenstein R, Cummings GE, Magder LS. Impact of influenza vaccination of schoolchildren on medical outcomes among all residents of 
Maryland. Vaccine. 2010 Nov;28(49):7737-42. https://doi.org/10.1016/j.va ccine.2010.09.064.

10. Medlmmune. Fluenz $z^{\circledR}$ intranasal live attenuated influenza vaccine: $E U$ summary of product characteristics. Available at the website: http://www. ema.europa.eu/docs/\%0Aen_GB/document_library/EPAR___Product_Informa tion/\%0Ahuman/001101/WC500103709.pdf. Accessed 10 Apr 2021.

11. Medlmmune LLC. FluMist ${ }^{\circledR}$ intranasal live attentuated influenza vaccine, 2010-2011 formula: US prescribing information. Available at the website: http://www.fda.gov/\%0Adownloads/BiologicsBloodVaccines/Vaccines/A pproved\%0AProducts/ucm123743.pdf. Accessed 10 Apr 2021.

12. AstraZeneca Canada. FluMist intranasal live attentuated influenza vaccine: Canadian product monograph. Available at the website: http://www.astra zeneca.ca/docu\%0Aments/ProductPortfolio/FLUMIST_PM_en.pdf. Accessed 10 Apr 2021.

13. Shim E, Brown ST, DePasse J, Nowalk MP, Raviotta JM, Smith K, et al. Cost effectiveness of influenza vaccine for U.S. children. Am J Prev Med. 2016 Sep;51(3):309-17. https://doi.org/10.1016/j.amepre.2016.02.027.

14. Skwarczynski M, Toth I. Non-invasive mucosal vaccine delivery: advantages, challenges and the future. Expert Opin Drug Deliv. 2020;17(4):435-7. https:// doi.org/10.1080/17425247.2020.1731468.

15. Carter NJ, Curran MP. Live Attenuated Influenza Vaccine (FluMist ${ }^{\oplus}$; Fluenz $z^{\mathrm{TM}}$ ). Drugs. 2011;71(12):1591-622. https://doi.org/10.2165/11206860-00000000000000.

16. Belshe RB, Edwards KM, Vesikari T, Black SV, Walker RE, Hultquist M, et al. Live attenuated versus inactivated influenza vaccine in infants and young children. N Engl J Med. 2007;356(7):685-96. https://doi.org/10.1056/NEJMoa 065368.

17. Public Health England. The National Childhood Flu Immunisation Programme 2019/20 - Information for healthcare practitioners. London: Gov. UK; 2019. Open Government Licence v3.0. Last accessed 2021 Apr 27. Available at the website: https://assets.publishing.service.gov.uk/ government/uploads/system/uploads/attachment_data/file/815744/ Childhood_flu_programme_information_for_healthcare_practitioners_201 9_2020.pdf

18. Ministero della Salute - Istituto Superiore di Sanità (ISS). Vaccinazione antinfluenzale: 2019-2020 - Coperture Vaccinali per 100 abitanti. 2021. Las accessed 2021 Apr 27. Available at the website: https://www.salute.gov.it/ imgs/C_17_tavole_19_5_0_file.pdf

19. Regione Lombardia - Giunta Direzione Generale Welfare. Prevenzione e controllo dell'influenza: raccomandazioni per la stagione 2020-2021: indicazioni in merito alla campagna antinfluenzale in Regione Lombardia. Milano: Gov. UK; 2019. Protocollo G1.2019.0028685 del 13/08/2019. Last accessed 2021 Apr 27. Available at the website: https://www.regione.lomba rdia.it/wps/wcm/connect/0f3c1600-818c-42ce-892b-94a625795400/nota201 928685 circolare +antinfluenzale.pdf?MOD=AJPERES\&CACHEID= ROOTWORKSPACE-0f3c1600-818c-42ce-892b-94a625795400-mTaLjL1.

20. McNaughton R, Lynn E, Osborne V, Coughtrie A, Layton D, Shakir S. Safety of intranasal Quadrivalent live attenuated influenza vaccine (QLAIV) in children and adolescents: a pilot prospective cohort study in England. Drug Saf. 2016;39(4):323-33. https://doi.org/10.1007/s40264-015-0384-7.

21. Agenzia Italiana del Farmaco (AIFA). Foglio illustrativo: informazioni per I'utilizzatore - Fluenz Tetra spray nasale, sospensione. 2021. Last accessed 2021 Apr 27. Available at the website: https://farmaci.agenziafarmaco.gov. it/aifa/servlet/PdfDownloadServlet?pdfFileName=footer_000690_043173_Fl. pdf\&retry $=0 \& s y s=m 0 b 113$

22. Istituto Nazionale di Statistica (Istat). II Censimento permanente della popolazione in Lombardia - Prima diffusione dei dati definitivi 2018 e 2019. 2021. Last accessed 2021 Apr 27. Available at the website: https://www.istat. it/it/files//2021/02/Censimento-permanente-Lombardia-2019.pdf

23. Organization for Economic Co-operation and Development (OECD). Education at a Glance 2019: OECD Indicators. Paris: OECD; 2019 Sep. (Education at a Glance). Last accessed 2021 Apr 27. Available at the website: https://www.oecd-library.org/education/education-at-a-glance-2019_ f8d7880d-en

24. Dipartimento per le politiche della famiglia; Istituto Nazionale di Statistica (Istat); Università Ca' Foscari Venezia - Facoltà di Economia; Consorzio Mipa (Consorzio per lo sviluppo delle metodologie e delle innovazioni nelle pubbliche amministrazioni). Nidi e servizi educativi per l'infanzia - Stato dell'arte, criticità e sviluppi del sistema educativo integrato 0-6. 2020. Last accessed 2021 Apr 27. Available at the website: https://www.istat.it/it/files//2 020/06/report-infanzia_def.pdf
25. Lindley MC, Boyer-Chu L, Fishbein DB, Kolasa M, Middleman AB, Wilson T, et al. The Role of Schools in Strengthening Delivery of New Adolescent Vaccinations. Pediatrics. 2008;121(Supplement 1):S46-54.

26. Heininger $U$. An internet-based survey on parental attitudes towards immunization. Vaccine. 2006 Sep;24(37-39):6351-5. https://doi.org/10.1016/j. vaccine.2006.05.029

27. Burnett RJ, Larson HJ, Moloi MH, Tshatsinde EA, Meheus A, Paterson P, et al. Addressing public questioning and concerns about vaccination in South Africa: a guide for healthcare workers. Vaccine. 2012;30:C72-8. https://doi. org/10.1016/j.vaccine.2012.03.037.

28. Robison SG, Osborn AW. The concordance of parent and child immunization. Pediatrics. 2017 May;139(5):e20162883. https://doi.org/10.1 542/peds.2016-2883

\section{Publisher's Note}

Springer Nature remains neutral with regard to jurisdictional claims in published maps and institutional affiliations.
Ready to submit your research? Choose BMC and benefit from:

- fast, convenient online submission

- thorough peer review by experienced researchers in your field

- rapid publication on acceptance

- support for research data, including large and complex data types

- gold Open Access which fosters wider collaboration and increased citations

- maximum visibility for your research: over $100 \mathrm{M}$ website views per year

At BMC, research is always in progress.

Learn more biomedcentral.com/submissions 